\title{
Extinção das TaRifas Reguladas no SeCtOR ElÉctrico
}

\section{ENQUADRAMENTO}

O sector eléctrico foi, historicamente, um sector de monopólio natural, controlado por uma única entidade a qual assegurava as diversas actividades relacionadas com o fornecimento da energia eléctrica, desde a sua produção, transporte e distribuição até ao abastecimento ao consumidor final. Esta é uma realidade que tem vindo a ser radicalmente alterada nas últimas décadas.

Após longos anos de actuação em regime de monopólio (público, privado ou misto) verticalmente integrado, verificaram-se em diversos países, em diferentes latitudes, várias experiências que resultaram em processos de desverticalização do sector com separação das suas actividades. $\mathrm{O}$ primeiro destes exemplos ocorreu no Chile no final da década de 70 do século $X X$, tendo as alterações consistido, basicamente, no fim dos monopólios da energia eléctrica e na introdução duma lógica de concorrência no mercado da electricidade. Esta passou a verificar-se na produção e na comercialização, mantendo-se como monopólios as actividades ligadas a infra-estruturas de rede como são o transporte e a distribuição.

\section{Mercado Regulado}

Também em Portugal a EDP funcionou, durante muito tempo, como a empresa vertical, que actuando em toda a cadeia, assegurava a produção, o transporte, a distribuição e a comercialização da energia eléctrica.

Esta realidade teve um ponto de inflexão significativo após a adesão de Portugal à, então, CEE. Em 1988 foi publicado um importante pacto legislativo que, entre outras inovações, consagrou a possibilidade de acesso ao sector pelos pequenos produtores privados na área da produção hidroeléctrica (mini-hídricas) e cogeração, obrigando a EDP a adquirir toda a energia por eles produzida a um preço regulado.

É também nesse período que cessa a exclusividade da concessão à EDP, sendo liberalizadas algumas das actividades do sector. Tal teve como objectivo a abertura do investimento no sector à iniciativa privada, permitindo canalizar verbas públicas para outros investimentos e, funcionando o mercado, permitir uma redução de preços com benefícios para os consumidores.

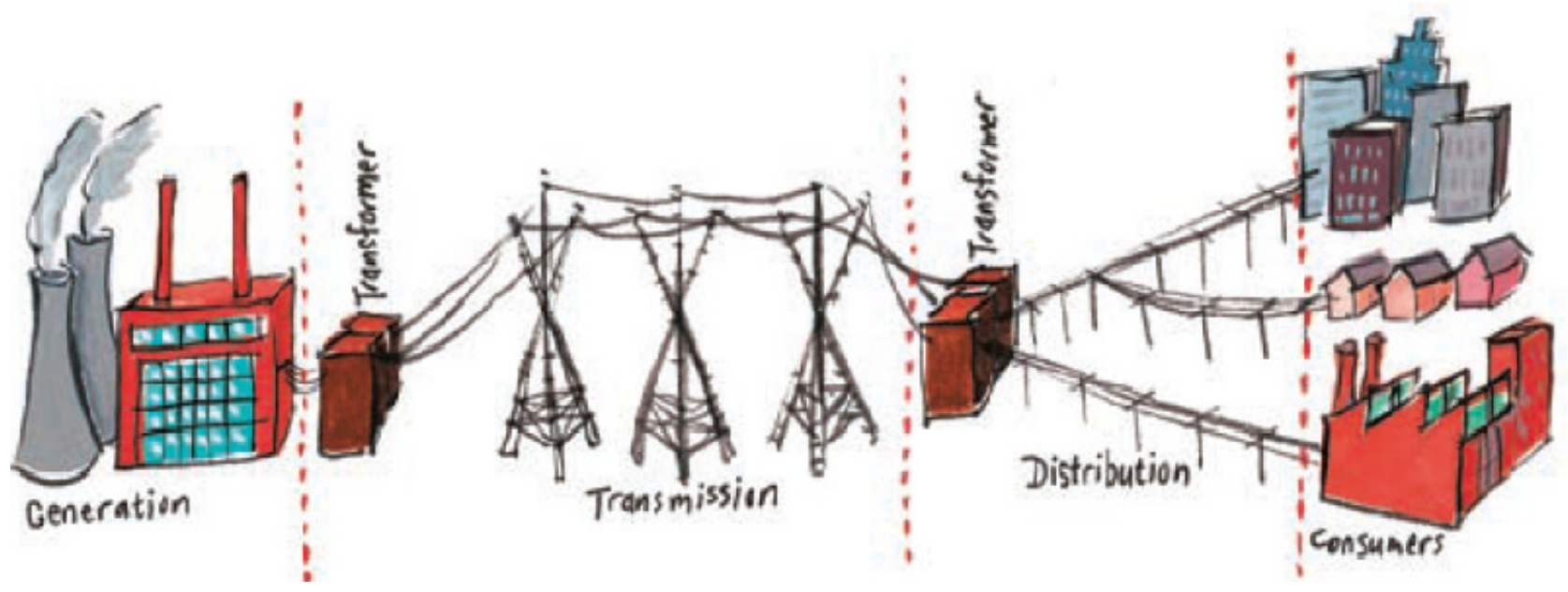

Fig. 1 - Actividades tradicionais no sector eléctrico 
Com uma progressiva abertura do sector a um ambiente de mercado concorrencial, emergiu o papel das entidades reguladoras como garantia de condições de igualdade de tratamento, de transparência e de não discriminação no acesso de produtores e de consumidores às redes de transporte e de distribuição. Em 1995 é criada a ERSE (Entidade Reguladora do Sector Eléctrico) pela publicação do Decreto-Lei n.ㅇ 187/95, de 27 de Julho.

Das suas competências constam:

- O estabelecimento dos valores das tarifas e preços para a energia eléctrica a aplicar anualmente

- A protecção dos interesses dos consumidores em relação a preços, serviços e qualidade do abastecimento

- Fomentar a concorrência

- Contribuir para uma utilização eficiente da energia eléctrica

Em 2002 são aprovados novos estatutos da ERSE pela publicação do Decreto-Lei no 97/2002 de 12 de Abril. A ERSE vê as suas competências alargadas com a inclusão da regulação das actividades relativas ao gás natural, passando a designar-se Entidade Reguladora dos Serviços Energéticos, embora mantendo a sigla original.

\section{Mercado liberalizado}

O processo de liberalização do sector eléctrico ocorreu, na maior parte dos países europeus, de modo faseado. Estes processos começaram tipicamente por contemplar os clientes dos níveis de tensão mais elevados e com maiores consumos. Também em Portugal, ainda na década de 90 do século passado, foi publicada legislação que abria o mercado apenas aos maiores clientes, tendo o processo sido progressivamente estendido a todos os clientes.

A abertura do mercado concorrencial teve como objectivo dinamizar o sector e impor-se como solução para o encontro entre a oferta e a procura, reflectindo-se numa expectável descida dos preços e melhoria da qualidade de serviço.

Este é um novo paradigma onde é concedida a cada consumidor a possibilidade de escolha do fornecedor, implicando alterações profundas em todo o enquadramento legislativo e regulatório bem como no modo de actuação das diversas entidades intervenientes. Potencia ainda o aparecimento de novos produtores e comercializadores, aumentando o número de intervenientes no sector e a complexidade de funcionamento do mesmo.

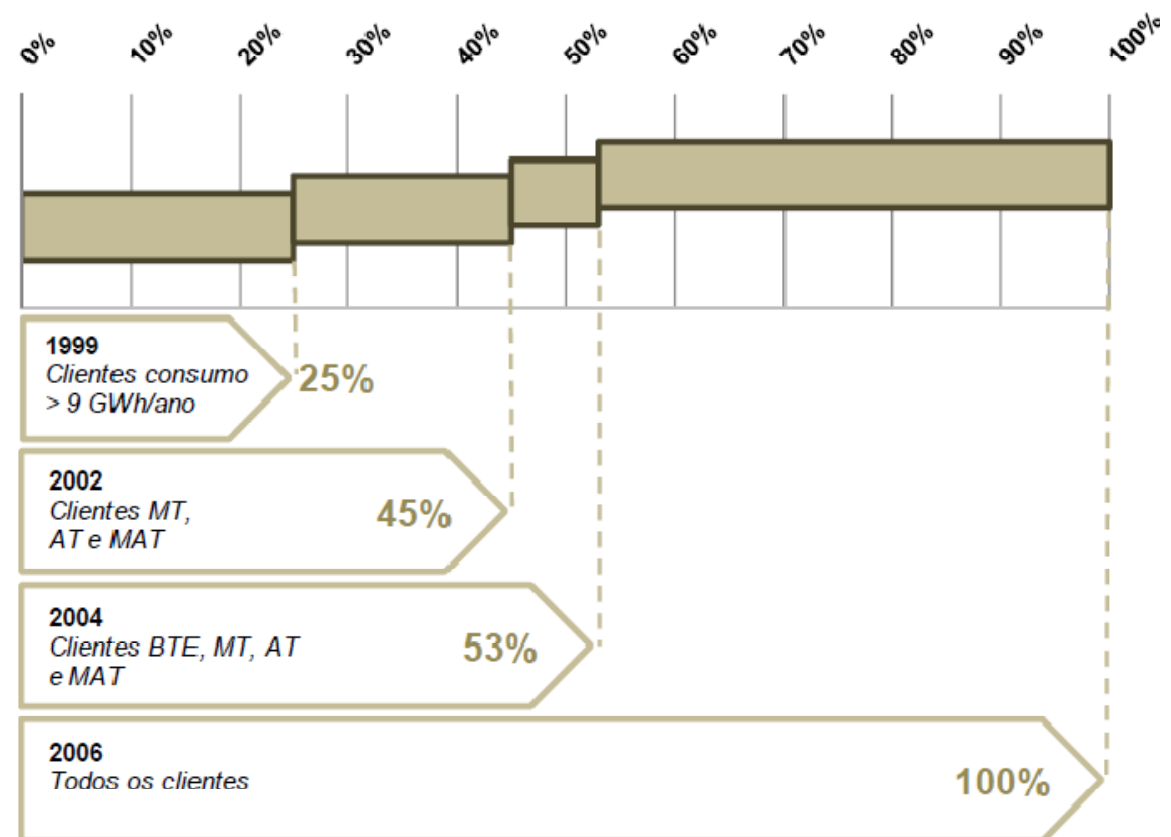

Fig. 2 - Calendário de abertura do mercado em Portugal (ERSE) 
A Directiva n.o 2003/54/CE, de 26 de Junho, definiu como data limite o dia 1 de Julho de 2007, para abertura do mercado a todos os clientes, independentemente dos seus consumos e da tensão de alimentação. A Directiva foi transposta para a ordem jurídica nacional pela publicação do Decreto-Lei n.o 29/2006, de 15 de Fevereiro. Aí, no âmbito da protecção dos consumidores, consagra-se a figura do comercializador de último recurso o qual assume o papel de garante do fornecimento de electricidade aos consumidores. Para Portugal continental foi estabelecida a data de 4 de Setembro de 2006 como aquela a partir da qual todos os clientes de energia eléctrica poderiam escolher livremente o seu fornecedor de energia eléctrica.

Este foi um processo que apresentou alguns percalços, nomeadamente, no final de 2007 com vários comercializadores a não aceitarem novos contratos de fornecimento de energia eléctrica nem renovarem contratos já existentes, alegando impossibilidade de concorrência com as tarifas reguladas. No final de 2008 e, principalmente, em 2009 e assistiu-se a um retorno de muitos clientes ao mercado liberalizado. Actualmente a adesão de novos clientes ao mercado apresenta-se como uma forte tendência.

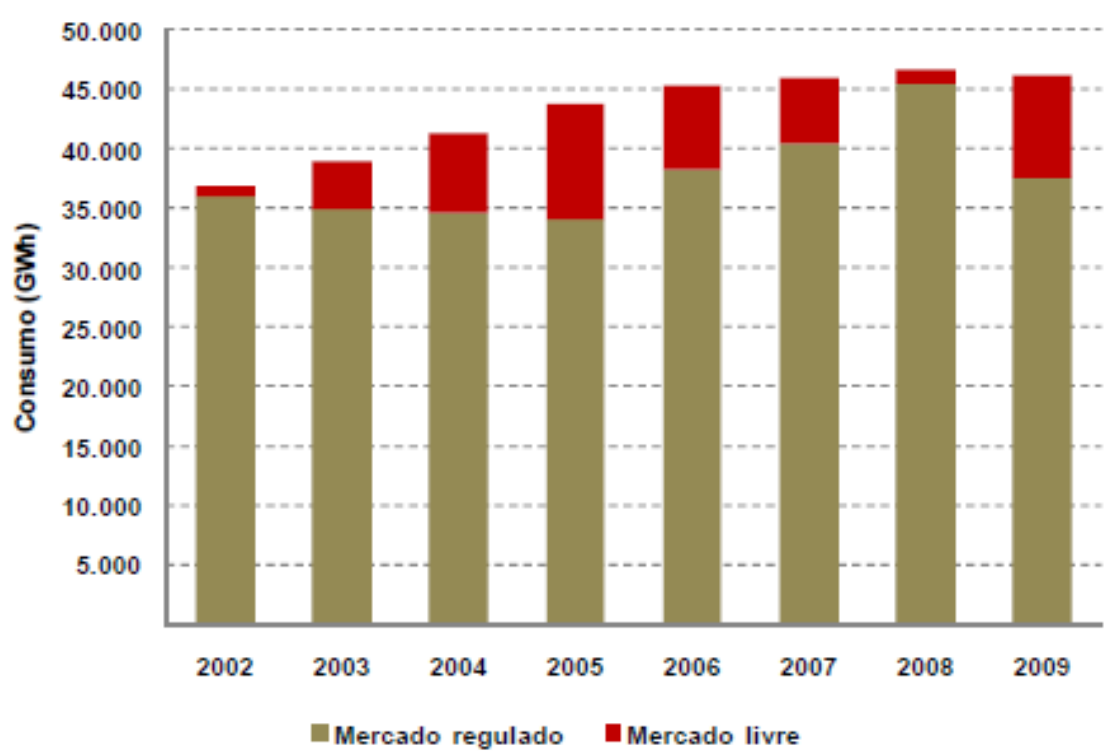

Fig. 3 - Evolução do consumo no mercado liberalizado (ERSE)

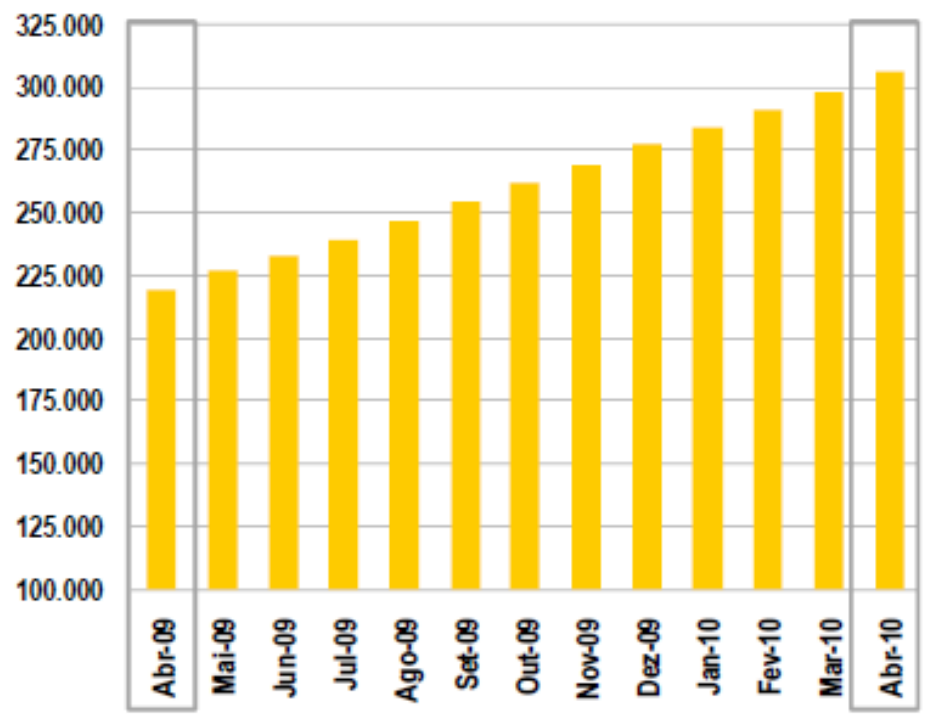

Fig. 4 - Número total de clientes no mercado liberalizado (ERSE) 


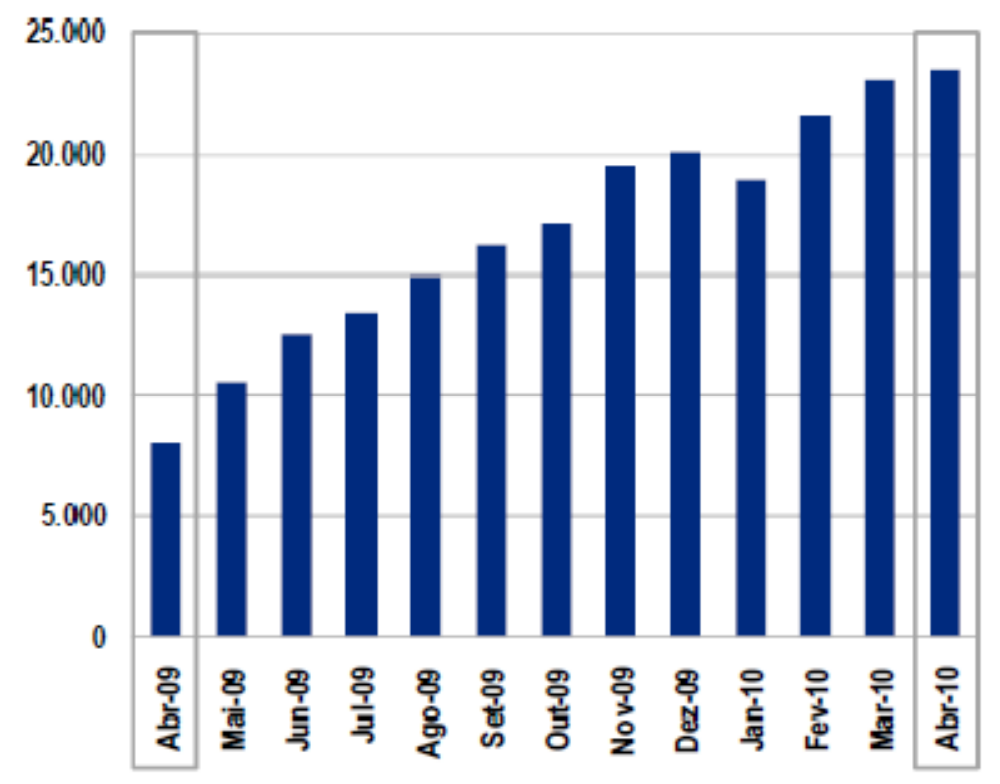

Fig. 5 - Consumo (GWh) no mercado liberalizado (ERSE)

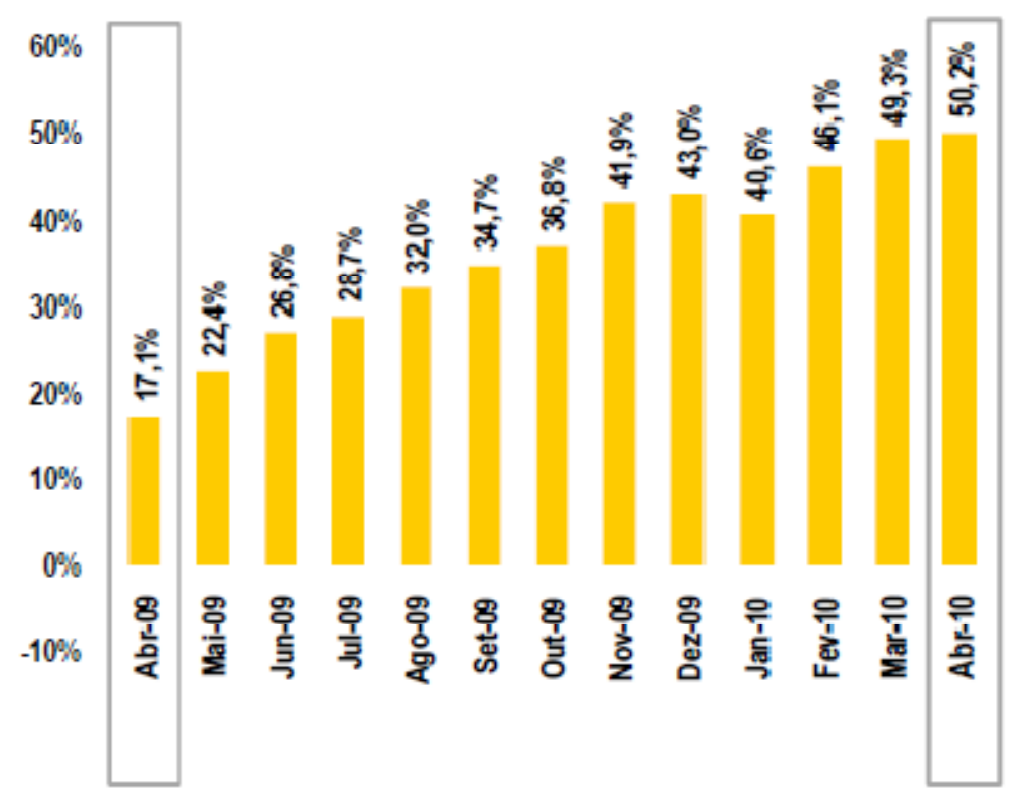

Fig. 6 - Peso relativo do consumo do mercado liberalizado (ERSE)

\section{Novo Modelo}

Com a recente publicação do Decreto-Lei n.o 104/2010 de 29 de Setembro verifica-se uma nova "revolução" no sector eléctrico, com a extinção das tarifas reguladas de fornecimento de energia eléctrica em Portugal continental, a partir de 1 de Janeiro de 2011. Por este diploma são abrangidos os clientes cuja alimentação seja em muito alta tensão (MAT), alta tensão (AT), média tensão (MT) ou baixa tensão especial (BTE). Significa que todos os clientes, com excepção daqueles que são alimentação em baixa tensão normal (BTN), deverão, no próximo ano, passar a ser abastecidos no âmbito do mercado liberalizado.

Esta é uma nova mudança de paradigma alterando, em pouco anos, o fornecimento no mercado liberalizado de um direito do consumidor para uma obrigação. 
A legislação prevê que os clientes que, à data de entrada em vigor do diploma, tivessem como fornecedor um comercializador de último recurso (CUR) e que entretanto não estabeleçam um contrato no mercado liberalizado, possam continuar a ser abastecido pelo CUR até à data limite de 31 de Dezembro de 2011. Para esse fim serão definidas pela ERSE tarifas transitórias determinadas pela soma das tarifas de energia, comercialização e acesso às redes, sendo agravada por uma percentagem a definir pela ERSE.

O CUR deverá notificar por carta registada todos os seus clientes até 30 dias após a entrada em vigor do Decreto-Lei n.o 104/2010 prestando-Ihes toda a informação necessária à mudança de comercializador. Este não é um processo automático cabendo a cada cliente consultar o mercado e optar por um comercializador do mercado liberalizado.

Os comercializadores autorizados a actuar no mercado liberalizado em Portugal obtém licenciamento junto da Direcção-Geral de Geologia e Energia. A ERSE disponibiliza na sua página de Internet (www.erse.pt) a lista com a identificação e os contactos dos comercializadores que se encontram a actuar no mercado.

A mudança de comercializador pode ser efectuada até quatro vezes em cada doze meses consecutivos, não podendo ser invocadas razões de ordem técnica para impedir essa mudança, nomeadamente as características dos contadores de energia.

De notar que, sendo o mercado livre, cada comercializador pode apresentar uma proposta comercial que poderá não ser facilmente comparável com a de um seu concorrente.

Cabe a cada cliente obter junto de cada comercializador os esclarecimentos necessários à sua decisão, garantindo que estão acautelados os seus interesses e que esses serão vertidos no contrato a estabelecer.
Deverão ainda ser tomados em conta outros aspectos como, por exemplo, que o ciclo mais adequado (semanal ou diário) ao funcionamento das instalações é o que consta na proposta, ou a explicitação de a quem competirá suportar eventuais alterações de custos com as tarifas de acesso às redes no decorrer da vigência do contrato.

\section{CONSIDERAçõEs FinaIS}

O sector eléctrico tem vindo a sofrer diversas alterações ao longo da sua existência tendencialmente no sentido do fomento da concorrência.

Em Portugal a manifestação mais recente dessa tendência é corporizada na publicação do Decreto-Lei n. 104/2010 que determina a extinção de tarifas reguladas com excepção dos consumidores domésticos. Esta é uma realidade que impõe aos clientes a procura de um comercializador em mercado liberalizado. Este é um desafio que poderá potenciar a oportunidade de cada cliente dedicar mais atenção aos aspectos relacionados com a energia eléctrica que consome, eventualmente conseguindo obter condições mais vantajosas e incrementar a eficiência energética e a utilização racional da energia nas suas instalações.

Esta não é contudo a única novidade no sector, havendo alterações ao nível da introdução de escalões no consumo de energia reactiva, já no início de 2011. Prevê-se ainda que, num futuro mais longínquo, se possam verificar alterações significativas no que diz respeito à qualidade de serviço e à poluição da responsabilidade de cada consumidor.

www.galpenergia.com Referências

www.erse.pt

www.edp.pt

www.dgge.pt

www.unionfenosa.pt

www.dre.pt 